\begin{tabular}{l}
$\begin{array}{c}\text { Yanbu Journal } \\
\text { of }\end{array}$ \\
$\begin{array}{l}\text { Engineering } \\
\text { and Science }\end{array}$ \\
\hline \hline ISSN: $1658-5321$
\end{tabular}$\quad$ Vol. 13, December $2016(1438 \mathrm{H})$

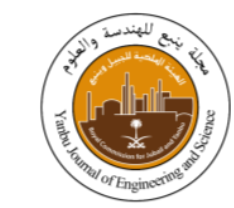

\title{
SYNTHESIS OF NEW 3-[(4-BROMO-5-METHYLTHIOPHEN-2-YL)METHYLENE AMINO]-2-ISOPROPYL QUINAZOLIN-4(3H)-ONE AND ITS CORROSION INHIBITION ON ZINC BY 2M HYDROCHLORIC ACID
}

\author{
Ali Abd Ali ${ }^{1}$, Rana Hammza ${ }^{1}$, Asim Balakit ${ }^{2}$, Ahmed Al-Amiery ${ }^{3}$, Emad Yousif \\ ${ }^{I}$ Department of Chemistry, College of Science, Al-Nahrain University, Baghdad, Iraq \\ ${ }^{2}$ College of Pharmacy, Babylon University, Babylon, Iraq \\ ${ }^{3}$ Environmental Research Centre, University of Technology, Baghdad, Iraq \\ Email: alassadi79@gmail.com
}

\begin{abstract}
The effect of 3-[(4-bromo-5-methylthiophen-2-yl) methylene amino]-2-isopropyl quinazolin-4(3-H) one (3-4-5QZ) as a corrosion inhibitor was studied using weight loss measurement. The rate of corrosion was found to be decreased with increasing inhibitor concentration. The adsorption of (3-4-5QZ) on the surface of zinc metal was also investigated according to the Freundlich model. The electronic property of (3-4-5QZ) inhibitor obtained by the semi-empirical quantum chemical calculations, using the PM3 method, revealed a satisfactory correlation with the experimental data.
\end{abstract}

Keywords: Corrosion inhibition, quantum chemical calculations, adsorption.

\section{INTRODUCTION}

Corrosion has been one of the common problems in chemical industry [1-4]. Several studies have been performed with respect to inhibiting the corrosion of metals and alloys including zinc [5-7]. In order to protect the surface of metals from corrosion, various organic and inorganic chemicals, such as azoles and thiazoles have been suggested [812]. These chemicals provide a barrier layer, which prevents the oxidation of metals by adsorption [13]. Additionally, typical organic inhibitors often contain an electron-rich atom, such as nitrogen and sulphur. These inhibitors can form coordination complexes with the metal cation [14-18] as shown in Figure 1. Organic inhibitors are commonly aromatic compounds with heteroatoms, as they comprise of delocalized $\pi$-electrons and unshared electrons on the heteroatoms, which allow the formation of coordination complexes [1, 19]. The adherence of inhibitor on the surface of the metal mediated by adsorption is highly influenced by the electronic properties of the whole inhibitor.

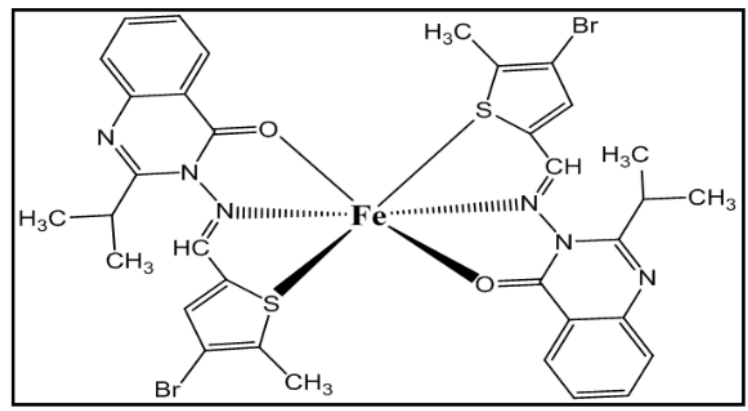

Fig. 1. A representation of the coordination complex between inhibitor and metal ion

Specifically, the electron density on the heteroatoms plays a major role in establishing a physical or chemical interaction with the metal [20]. Therefore, the selection of an inhibitor is based solely on its capacity to bind 
to the surface of the metal and retard the corrosion. Hence, inhibitors with a robust adsorption capacity are considered good inhibitors [21]. Herein, a comprehensive investigation was carried out for clearly understanding the chemistry of adsorption of (3-4-5QZ) inhibitor on the surface of zinc metal, especially, the electronic properties. To the best of our knowledge, the plethora of studies on the corrosion of zinc has not yet clearly elucidated the surface chemistry at the solid-liquid interface. In this article, we present a systematic study on the adsorption of (3-4-5QZ) on the surface of zinc metal before exposure to corrosives $(\mathrm{HCl}$ in the present study). Furthermore, the optimal conditions for the best protection of the surface were evaluated based on the effect of temperature and thermodynamic parameters of adsorption.

\section{EXPERIMENTAL}

\subsection{Materials AND METHOdS}

Zinc strips obtained from zinc-graphite batteries were prepared with the following dimensions $(8 \mathrm{~cm} \times 2 \mathrm{~cm} \times 0.5 \mathrm{~mm} ; \mathrm{L} \times W$ $\times \mathrm{H}$, respectively). $\mathrm{HCl}(35-37 \%$, AR-grade) was obtained from Sigma-Aldrich. Ethanol (96\%), absolute ethanol (98.99\%), and acetone were procured from Merck. All chemicals were used without further purification. Ultrapure water $(18.2 \Omega \mathrm{cm})$ was used for preparing the solutions and washings. A stock solution of $1000 \mathrm{ppm}$ of (3-4-5QZ) was sequentially diluted to $500,400,300$, 200, and $100 \mathrm{ppm}$. Since (3-4-5QZ) was readily soluble in ethanol, all the solutions were prepared in absolute ethanol. The volumetric flasks were sealed with parafilm to minimize the error in the concentration due to evaporation. Zinc strips were washed sequentially with acetone, ethanol (96\%), and ultrapure water, followed by oven-drying at
$60{ }^{\circ} \mathrm{C}$. These strips were scrubbed by emery paper and washed with acetone, ethanol, and water, dried, and stored in desiccators until further use. The zinc strips were weighed and immersed in a $2 \mathrm{M} \mathrm{HCl}$ solution over a period of $200 \mathrm{~min}$ at $20 \mathrm{~min}$ intervals.

\subsubsection{Synthesis of (3-4-5QZ)}

The (3-4-5QZ) was synthesized according to the established protocol [22].

\subsubsection{Quantum Chemical Calculations}

The electronic properties of (3-4-5QZ) inhibitor were studied using quantum chemical calculation by HyperChem7 software. The (3-4-5QZ) molecule was geometrically optimized by the semi-empirical method. Electronic properties, such as the energy of the highest occupied molecular orbital (HOMO) and the energy of the lowest molecular orbital (LUMO), the energy gap $(\Delta \mathrm{E})$, and the Mulliken charges on the backbone atoms of the synthesized (3-4-5QZ) inhibitor were also evaluated.

\subsubsection{Adsorption of (3-4-5QZ) on the zinc metal}

The zinc strip was immersed in each (3-45QZ) solution $(100,200,300,400$, and 500 ppm, respectively), and allowed to equilibrate for $140 \mathrm{~min}$. Consequently, the strips were immersed in $2 \mathrm{M} \mathrm{HCl}$, and the differences in the weight for $200 \mathrm{~min}$ at $20 \mathrm{~min}$ interval were estimated. The coating was performed at different temperatures: 298, 303, 308, 313, and $323 \mathrm{~K}$.

\section{RESULTS AND DISCUSSION}

\subsection{WeIGHT LosS MEASUREMENTS}

The zinc strip was immersed in $2 \mathrm{M} \mathrm{HCl}$ in the absence of inhibitor over a period of 200 $\mathrm{min}$ at $20 \mathrm{~min}$ interval. The difference in the weight $(\mathrm{g})$ plotted against the time ( $\mathrm{min}$ ) indicated that the weight loss increased dramatically with time Figure 2. 


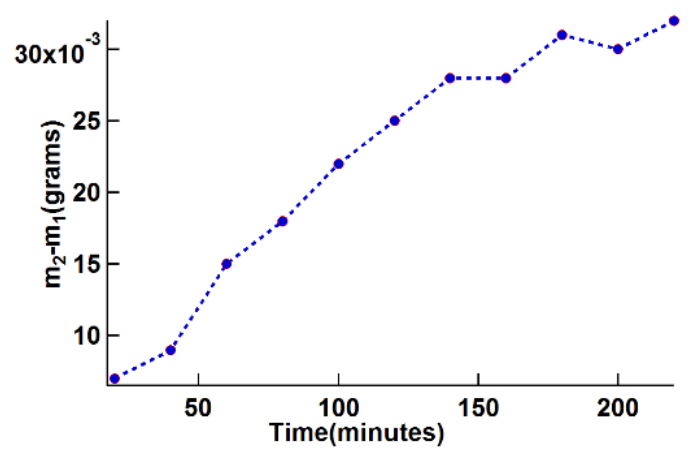

Fig. 2. Difference in weight after immersion of zinc metal in $2 \mathrm{M}$ $\mathrm{HCl}$ solution

Thus, it can be inferred that the zinc metal was oxidized as a result of the prolonged exposure to $\mathrm{HCl}$, which in turn led to the formation of $\mathrm{Zn}^{2+}$.

\subsubsection{Synthesis and Characterisation of (3-4-5QZ)}

The synthesis was initiated by the bromination of 2-methylthiophene to obtain 3,5-dibromo-2-methylthiophene, which is then converted to 3-bromo-2methylthiophene-5-carboxaldehyde, the desired aldehyde. The structures of the products described above were confirmed by ${ }^{1} \mathrm{HNMR},{ }^{13} \mathrm{CNMR}$, mass spectroscopy, and FT-IR techniques. The target imine (Schiff base) was synthesized by the reaction of 3bromo-2-methylthiophene-5-carboxaldehyde with 1 mole equivalent of 3amino-2isopropylquinazolin- $4(3 \mathrm{H})$-one by microwave conditions (Scheme 1).

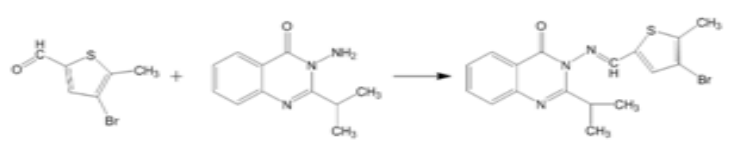

Scheme.1. Synthesis of (3-4-5QZ)

The ${ }^{1} \mathrm{HNMR}$ analysis of the product showed that the singlet at $\delta=9.69 \mathrm{ppm}$ corresponding to the aldehydic hydrogen disappeared and a new singlet at $\delta=9.15$ ppm, corresponding to the proton of the $\mathrm{NH}$ group, was observed in addition to all the other predicted signals. The ${ }^{13} \mathrm{C}$ NMR spectrum showed that the signal at $\delta=181.6$ corresponding to the carbon of the carbonyl group disappeared and the signal at $\delta=160.6$ corresponding to the carbon of the $\mathrm{C}=\mathrm{N}$ group was observed; all the other predicted signals were also observed. Finally, the formula of the product was confirmed by the high-resolution mass spectrometry, which displayed a peak at $\mathrm{m} / \mathrm{z}=389.0198$ that correlated with the calculated value, 389.0197 for $\mathrm{C}_{17} \mathrm{H}_{16} \mathrm{~N}_{3} \mathrm{OS}^{79} \mathrm{Br}$. Thus, the product obtained was remarkably pure with a high yield of $88 \%$.

\subsubsection{Quantum Chemical Calculations}

This theoretical study aimed to provide information about the electron configuration of the (3-4-5QZ) by quantum chemical calculations and investigate the correlation between molecular structure and inhibition efficiency. All the computations for geometric optimization were performed using the semiempirical calculations with PM3 method using the complete HyperChem Program Figure. 3(a), Figure 3(b), Figure 3(c), and Figure 3(d). This computational method has yielded satisfactory results previously [23].
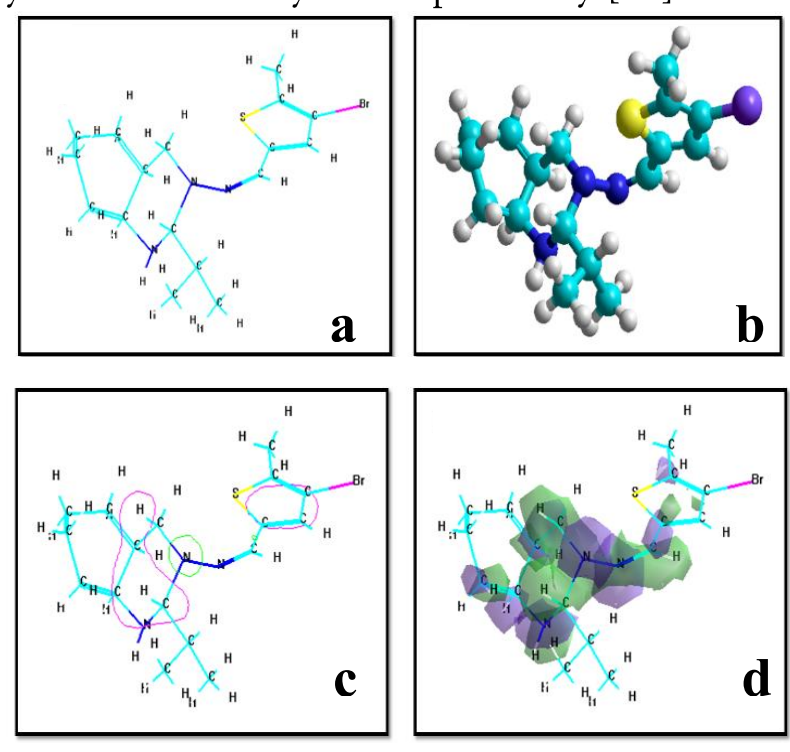

Fig. 3(a). The geometrically optimized structure of (3-4-5QZ) in stick model. (b): The geometrically optimized structure of (3-4-5QZ) in ball and stick model. (c): The HOMO and LUMO as 2D for (34-5QZ). (d): The HOMO and LUMO as 3D contours for (3-45QZ). 
The simplest way to compare the inhibition efficiency of a compound is to analyze the energies of HOMO and LUMO. The calculated energies $\mathrm{E}_{\mathrm{HOMO}}, \mathrm{E}_{\mathrm{LUMO}}$, energy gap, $\left(\Delta \mathrm{E}=\mathrm{E}_{\mathrm{LUMO}}-\mathrm{E}_{\mathrm{HOMO}}\right)$ and other indices are presented in Table 1.

TABLE 1: THE CALCULATED ENERGY PARAMETERS FOR (3-4-5QZ) INHIBITOR USING PM3 METHOD

\begin{tabular}{|c|c|c|c|c|}
\hline Inhibitor & $\begin{array}{c}\text { HOMO } \\
(\mathrm{eV})\end{array}$ & $\begin{array}{c}\text { LUMO } \\
(\mathrm{eV})\end{array}$ & $\begin{array}{c}\Delta \mathrm{E} \\
(\mathrm{eV})\end{array}$ & $\begin{array}{c}\mu \\
(\text { Debye })\end{array}$ \\
\hline $3-4-5 \mathrm{QZ}$ & -8.87 & 0.90 & -7.91 & 1.96 \\
\hline
\end{tabular}

The absolute value of energy gap $(\Delta \mathrm{E})$ between the HOMO and LUMO energy levels of the synthesized (3-4-5QZ) was low, which indicated a good correlation with the experimental data. The $\Delta \mathrm{E}$ provides optimal efficiency of inhibition. The availability of high electron density on the sulphur and nitrogen atoms in the (3-4-5QZ) inhibitor, Figure 4 facilitates the inhibition of corrosion as it retards the formation of zinc ions as a result of the oxidation process. The retardation (corrosion inhibition) can be explained by the following equilibrium:

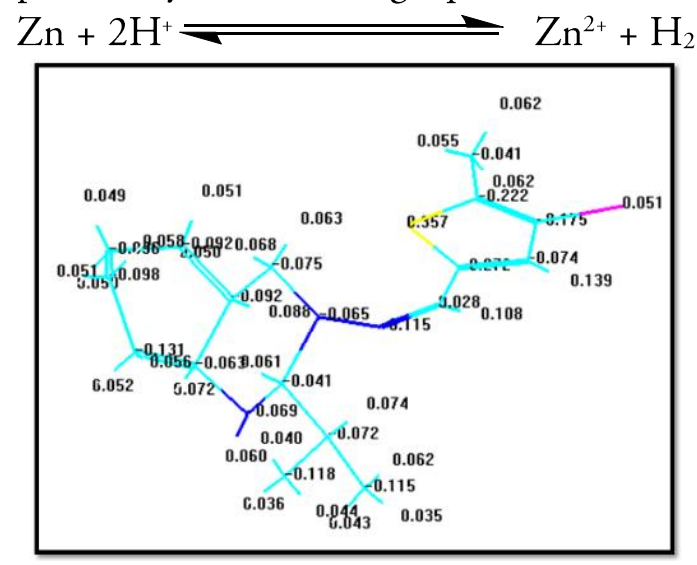

Fig. 4. Formal charges of the (3-4-5QZ)

Adsorption of (3-4-5QZ) on the Zinc Metal: The adsorption of (3-4-5QZ) was studied via introducing it to the surface of zinc metal at different concentrations of 100, 200, 300, 400 , and $500 \mathrm{ppm}$. The maximum adsorption percentage was observed at $400 \mathrm{ppm}$. The zinc strips were immersed in different inhibitor concentrations, and the UV-visible absorption was monitored at $384 \mathrm{~nm}$ before and after the immersion at different time intervals up to $160 \mathrm{~min}$, which is the typical contact time for establishing the adsorption equilibrium Figure 5. The equilibrium concentration of the adsorbed inhibitor was calculated as follows:

$$
\mathrm{Q}_{\mathrm{e}}=\mathrm{V}_{\text {sol }}\left(\mathrm{C}_{\mathrm{o}}-\mathrm{C}_{\mathrm{e}}\right) / \mathrm{m}
$$

Where Qe, Co, Ce, Vsol, and $\mathrm{m}$ represent the quantity of the adsorbate $(\mathrm{mg} / \mathrm{g})$, initial concentration of the adsorbate solution $(\mathrm{mg} / \mathrm{L})$, concentration of the adsorbate solution at equilibrium $(\mathrm{mg} / \mathrm{L})$, total volume of the adsorbate solution (L), and weight of the adsorbent $(\mathrm{g})$, respectively.

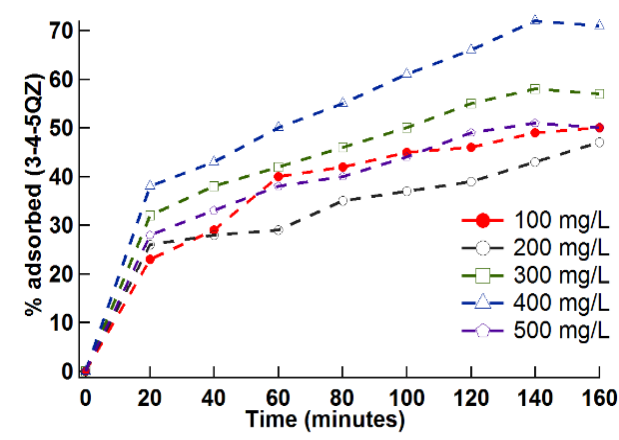

Fig. 5. Contact time of (3-4-5QZ) adsorption for $100-500 \mathrm{mg} / \mathrm{L}$ at $298 \mathrm{~K}$

The adsorption of (3-4-5QZ) was maximum at $400 \mathrm{ppm}$ Figure 6, which indicated that this concentration fulfilled the maximum surface coverage for the zinc metal. However, the adsorption of (3-4-5QZ) did not demonstrate a higher adsorption percentage. This phenomenon that might be attributed to the remarkably large size of the molecule, such that the steric hindrance between the molecules in solution was the key limiting factor for adsorption in this case. The concentration of $400 \mathrm{ppm}$ was selected as optimum for the subsequent experiments. The systematic observation and study of the 
surface chemistry of (3-4-5QZ) adsorption ascribed it as chemisorption rather than a weak physical interaction. Hence, the Langmuir adsorption isotherm, suggesting that the surface active sites of the adsorbent have similar adsorption energy, did not serve as an appropriate model for rationalizing the adsorption of (3-4-5QZ). Therefore, another model, Freundlich isotherm, was employed. This model postulates that the active sites on the surface have different adsorption energies, which is possibly the case in zinc. The heterogeneity of the zinc surface causes multilayer adsorption instead of only a monolayer. The Freundlich model can be expressed mathematically by the following formula [24]:

$$
\log \mathrm{Q} e=\log \mathrm{K}_{\mathrm{F}}+1 / \mathrm{n}(\log \mathrm{Ce})
$$

Where Qe and Ce are the adsorbate quantity at equilibrium $(\mathrm{g})$ and the concentration of adsorbate at equilibrium $(\mathrm{mg} / \mathrm{L})$. The $\mathrm{KF}$ and $1 / \mathrm{n}$ are defined as Freundlich constants, where KF is the adsorption capacity, and $1 / \mathrm{n}$ represents the adsorption intensity. Herein, the $\mathrm{KF}=2.78$ and $1 / \mathrm{n}=-1.22$, which validates the Freundlich model and confirms that the adsorption does not stop at the monolayer.

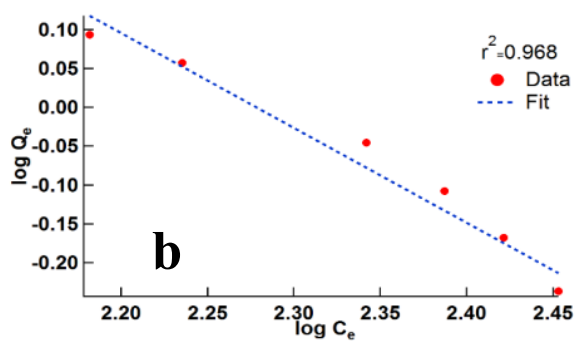

Fig. 6. (a): Freundlich adsorption isotherm of (3-4-5QZ) at $298 \mathrm{~K}$.

(b): Linear plot of Freundlich adsorption isotherm at $298 \mathrm{~K}$.

The S-shaped adsorption isotherm in Figure 6(a) confirms the assumptions that the adsorption model can be satisfactorily established using the Freundlich isotherm, wherein a linear trend was obtained when $\log$ Qe was plotted against log Ce Figure 6(b). As described above, the optimum concentration for (3-4-5QZ) was $400 \mathrm{ppm}$ for maximum adsorption. In addition, the corrosion rate (CR) was also reduced as compared to the other concentrations Figure 7.

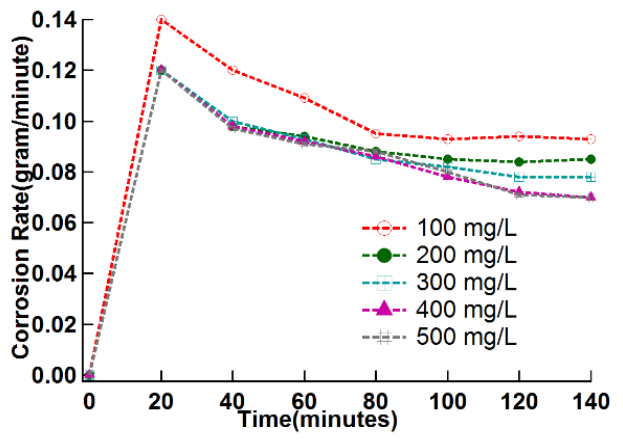

Fig. 7. Corrosion rate of zinc after the addition of different (3-45QZ) concentrations, $100-500 \mathrm{mg} / \mathrm{L}$ at $298 \mathrm{~K}$

Therefore, it could be unequivocally concluded that the multilayer formation at $400 \mathrm{ppm}$ prevented the corrosion of zinc metal due to maximum adsorption, thereby satisfactorily matching the Freundlich model of adsorption. In order to optimize the corrosion inhibition, the adsorption of (3-45QZ) was investigated at different temperatures (298-323 K). The percentage of adsorbed (3-4-5QZ) was found to decrease with increasing temperature Figure 8.

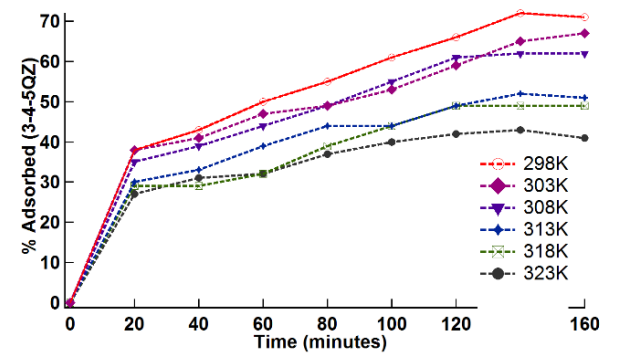

Fig. 8. Effect of temperature on the adsorption of (3-4-5QZ)

In the present case, the adsorption is exothermic; however, the desorption occurs with increasing temperature; the limited adsorption can be attributed to the steric hindrance between (3-4-5QZ) molecules in solution. Consequently, the increasing temperature will increase the kinetic energy of 
the molecules, which in turn will lead to the collision with zinc and among each other. This assumption was further confirmed by implementing thermodynamic calculations (Equations 3-6) for $\Delta \mathrm{H}, \Delta \mathrm{G}$, and $\Delta S$ (enthalpy, Gibbs free energy, and entropy, respectively) as shown in Table 2.

$$
\begin{aligned}
& \mathrm{b}=\mathrm{a} \cdot \exp (\Delta \mathrm{H} / \mathrm{RT}) \\
& \ln \mathrm{b}=\ln \mathrm{a}-\Delta \mathrm{H} / \mathrm{RT} \\
& \ln \mathrm{a}=\Delta \mathrm{S} / \mathrm{R} \\
& \Delta \mathrm{G}=\Delta \mathrm{H}-\mathrm{T} \Delta \mathrm{S}
\end{aligned}
$$

Equation 3 is defined as Arrhenius equation, where $b$ is the maximum adsorption quantity at the optimum concentration (400 ppm), a is the pre-exponential factor, $\mathrm{R}$ is the gas constant $\left(8.314 \mathrm{~J} \cdot \mathrm{K}^{-1} \cdot \mathrm{mol}^{-1}\right)$, and $\mathrm{T}$ is the temperature in Kelvin. The plot of $\ln \mathrm{b}$ against the reciprocal of temperature (Kelvin) revealed a linear trend with the correlation coefficient $\left(r^{2}\right)$ as shown in Figure 9.

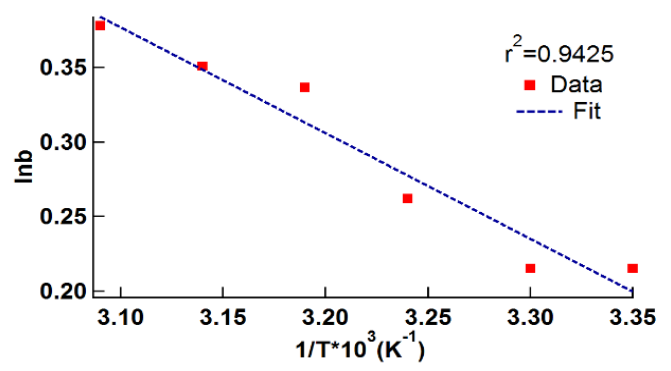

Fig. 9. Plot of $\ln \mathrm{b} v s$. the reciprocal of temperature

Table 2 demonstrates that the adsorption process was exothermic, ordered, and spontaneous at $298 \mathrm{~K}$, which is the room temperature. The change in the enthalpy values indicates that the adsorption was chemisorption and could occur at moderate temperatures as indicated by the altered free energy values. The elevated positive entropy values with increasing temperature indicated a disordered system, which might be attributed to the prolonged duration required for the optimized spatial arrangement of (3-4-5QZ) molecules.
TABLE 2: THE THERMOdYNAMICS PROPERTIES OF ADSORPTION AT DIFFERENT TEMPERATURE

\begin{tabular}{|c|c|c|c|}
\hline $\mathrm{T}(\mathrm{K})$ & $\boldsymbol{\Delta} \mathbf{H}^{\mathbf{a}}$ & $\boldsymbol{\Delta} \mathbf{S}^{\mathbf{b}}$ & $\Delta \mathrm{G}^{\mathbf{c}}$ \\
\hline 298 & -5.84 & +1.78 & -535.69 \\
\hline 303 & -5.94 & +1.77 & -541.65 \\
\hline 308 & -5.92 & +2.16 & -670.89 \\
\hline 313 & -5.82 & +2.78 & -875.34 \\
\hline 318 & -5.88 & +2.89 & -962.81 \\
\hline 323 & -5.90 & +3.12 & -1014.95 \\
\hline
\end{tabular}

$\mathrm{a} \& \mathrm{c}$ in $\mathrm{kJ} \cdot \mathrm{mol}^{-1}$, and b in $\mathrm{kJ} \cdot \mathrm{mol}^{-1} \cdot \mathrm{K}^{-1}$

This arrangement is governed by factors, such as the electrostatic repulsion between the attached molecules to the surface, the surface capacity, and the diffusion speed of (3-4-5QZ) from the bulk solution towards the surface of zinc. After the surface reaches the maximum capacity of accommodation, the excessive amount of (3-4-5QZ) molecules remains free in the solution; the optimum concentration of (3-4-5QZ) inhibitor (400 ppm) was selected according to the previous observations. Consequently, the high entropy of the system as a result of high temperature occurs due to the desorption of (3-4-5QZ). Nevertheless, it does not necessarily designate adsorption as a weak physical interaction (physisorption). Here, we propose that the chemisorption in this system occurs via equilibrium as shown in the following equation:

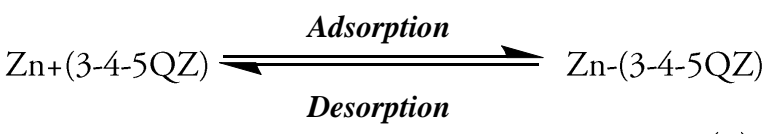

The temperature increment will shift the equilibrium to the left-hand side, which is unfavorable since our major objective is to provide all the necessary conditions for the 
adsorption of (3-4-5QZ) on the surface, consequently inhibiting the corrosion.

\section{CONCLUSIONS}

In the present study, the protection of zinc by introducing (3-4-5QZ) was largely successful. The results showed a low corrosion rate upon the addition of the optimum concentration of the inhibitor at $400 \mathrm{ppm}$. The thermodynamics revealed that the adsorption process was exothermic, spontaneous, and ordered within the moderate temperature regime $(298-303 \mathrm{~K})$. The adsorption was chemisorption that followed a Freundlich model, exhibiting a multilayer formation.

\section{ACKNOWLEDGMENT}

We thank the College of Science, Department of Chemistry for the financial and technical support for this study.

\section{REFERENCES}

[1] Agarwal, Y.K., Talati, J.D., Shah, M.D., Desai, M.N., Shah, N. K., "Schiff bases of ethylenediamine as corrosion inhibitors of zinc in sulphuric acid", Corr.Sci., 46, 2003, 633-651. DOI: $10.1016 / S 0010938 X(03) 00174-4$

[2] Algaber, S., El-Nemna, E.M., Saleh, M.M., 2004, "Effect of octylphenol polyethylene oxide on the corrosion inhibition of steel in $0.5 \mathrm{M}$ H2SO4", Mater. Chem. Phys., 86, 26-32. DOI: 10.1016/j.matchemphys.2004.01.040

[3] Lebrini, M., Bentiss, F., Vezin, H., Lagrenee, M., "Inhibiting effect of some oxadiazole derivatives on the corrosion of mild steel in perchloric acid solution", Appl. Surf. Sci., 252, 2005, 950-958. DOI: 10.1016/j.apsusc.2005.01.160

[4] Lowmunkhong, P., Ungthararak, D., Sutthivaiyakit, P., "Tryptamine as a corrosion inhibitor of mild steel in hydrochloric acid solution", Corr. Sci., 52, 2010, 30-36. DOI: 10.1016/j.corsci.2009.08.039

[5] Abdallah M, "Ethoxylated fatty alcohols as corrosion inhibitors for dissolution of zinc in hydrochloric acid", Corr. Sci., 45, 2003, 2705. DOI: $10.1016 / S 0010-938 X(03) 00107-0$
[6] Talati, J.D., Desai, M.N. and Shah, N.K., "Metasubstituted aniline- $\mathrm{N}$ salicylidenes as corrosion inhibitors of zinc in sulphuric acid", Mater. Chem.Phys., 93(1), 2005 (a), 54-65. DOI: 10.1016/j.matchemphys.2005.02.004

[7] Wang, L., Pu, J.-X., and Luo, H.C., "Corrosion inhibition of zinc in phosphoric acid solution by 2mercaptobenzimidazole", Corr.Sci. 45(4), 2003a, 677-83. DOI: 10.1016/S0010-938X(02)00145-2

[8] Ali, A., Abdullah, B., Yousif, E., "Corrosion inhibition of zinc metal in $4 \mathrm{M}$ hydrochloric acid solution by using naproxen drug as an inhibitor", Yanbu J. Eng. Sci.,7, 2012, 37-41.

[9] Herrag, L., Chetouani, A., Elkadiri, S., Hammouti, B., \& Aouniti, A. "Pyrazole derivatives as corrosion inhibitors for steel in hydrochloric acid." Portugaliae Electrochimica Acta 26.2 (2008): 211-220.

[10] Gomma, G.K., Wahdan, M.H., "Effect of copper cation on electrochemical behaviour of steel in presence imidazole in acid medium", Mater. Chem. Phys., 47, 1997, 176-183.DOI: 10.1016/S02540584(97)80048-XGao, Y., Yue, Q., Gao, B., Sun, Y., Wang, W., Li, Q., and Wang, Y., Comparisons of Porous, Surface Chemistry and Adsorption Properties of Carbon Derived from Enteromorphaprolifera Activated by $\mathrm{H} 4 \mathrm{P} 2 \mathrm{O} 7$ and $\mathrm{KOH}$, Chemical Engineering Journal, 232, 582-590, 2013.

[11] Ouafi, A. E., Hammouti, B., Oudda, H., Kertit, S., Touzani, R., Ramadani, A., "New bipyrazole derivatives as effective inhibitors for the corrosion of mild steel in $1 \mathrm{M} \mathrm{HCl}$ medium", Anti-Corr. Meth. Mat., 49, 2002, 199-204. DOI: 10.1108/00035590210426463

[12] Osama, B., Ali, A., Dhea Z., Yousif, E., "Corrosion inhibition of zinc metal in hydrochloric acid solution by using ciprofloxacin drug as an inhibitor", Al-Nahrain J. Sci., 17(2), 2014 , 26-31. http://jnus.org/pdf/1/2015/1/1076.pdf

[13] Bentiss, F., Lebrini, M., Lagrenee, M., "Thermodynamic characterisation of metal dissolution and inhibitor adsorption processes in mild steel 2,5-bis(n-thienyl)-1,3,4thiazoles/hydrochloric acid system", Corr.Sci.,47,2005,2915.DOI:10.1016/j.corsci.2 005.05.034

[14] Al-Amiery, A., Al-Majedy, Y., Kadhum, A. H., and Mohamad, A., "New Coumarin Derivative as 
an EcoFriendly Inhibitor of Corrosion of Mild Steel in Acid Medium”, Molecules, 20(1), 2015, 366. DOI: $10.3390 /$ molecules20010366

[15] Junaedi, A. Kadhum, A. Al-Amiery, A., Mohamad, A., Takriff, M., "Synthesis and characterization of novel corrosion inhibitor derived from oleic acid: 2-Amino 5-Oleyl-1, 3, 4Thiadiazol (AOT)”, Int. J. Electrochem. Sci. 7, 2012, 3543 www.electrochemsci.org/papers/vol7 17043543.pdf

[16] Lukas N, Lukas R, Dorota W, Vedran M, Pavel , Jiri K, Ruttkay-N, Vojtech A, Rene K," Behavior of UV Sensitive Zinc Complexes Revealed by Using Electrochemistry and Spectroscopy”, Int. J. Electrochem. Sci., 10, 2015, 1696-1707.

[17] Musa, A., Ahmoda, W., Al-Amiery, A., Kadhum, A., Mohamad, A.B, "Quantum chemical calculation for the inhibitory effect of compounds", J. Str. Chem., 54(2), 2013, 301. DOI:10.1134/S0022476613020042

[18] Al-Amiery, A., Kadhum, A., Mohamad, A., Junaedi, S., "A novel hydrazinecarbothioamide as a potential corrosion inhibitor for mild steel in HCl”, Mater, .6, 2013, 1420.

[19] Ebenso, E.E., Eddy, N.O., Odiongenyi, A. O., "Corrosion inhibition and adsorption properties of methocarbamol on mild steel in acidic medium”, Port. Electrochim. Acta., 27, 2009, 1322.

[20] Afidah, A., Rahim, E., Rocca, J., Steinmetz, M.J., Kassim, R.A., Ibrahim, S., "Mangrove tannins and their flavonoid monomers as alternative steel corrosion inhibitors in acidic medium”, Ann. Of Forest Sci., 49, 2015, 402-417.
[21] Ngiik, T.C., Adsorption of Methylene Blue By Activated Carbon Prepared from Waste Tire Powder, Thesis, Faculty of Chemical Engineering, Universiti Teknologi Malaysia, January 2013.

[22] Sankarapapavinasam, S., Pushpanden, F., Ahmed, M.F., "Inhibition of mild steel corrosion in phosphoric acid solution by triazole derivatives", Corr. Sci, 2006, 608-616 DOI: 10.1016/j.corsci.2005.02.007

[23] Balakit A., Ahmed A., El-Hiti G., Smith K., Yousef E., " Synthesis of new thiophene derivatives and their use as photostabilisers for rigid poly(vinylchloride)", Int. J. Poly. Sci., (1), 2015, 1-10. DOI:10.1155/2015/510390

[24] Stewart, J.,James, P. J.,"Optimisation parameters for semi-empirical methods II. Applications", J. Comput. Chem., 10(2), 1989, 221-264. www.dtic.mil/dtic/tr/fulltext/u2/a209386.pdf

[25] Gupta, Nitish, Amritphale, S.S., Chandra, N., Biores. Technol, "Removal of $\mathrm{Zn}$ (II) from aqueous solution by using hybrid precursor of silicon and carbon”, 101(10), 2010, 3355-3362. DOI: 10.1016/j.biortech.2009.12.024

[26] Ali A., Khulood A., "Adsorption studies of Linear alkylbenzene sulphonate (LAS) by using Iraqi bentonite clays", Iraqi. J.Sci, 50(2), 2008, 144151. http://www.iasj.net/iasj?func=fulltext $\&$ aId $=2614$

[27] Li, W., He, Q., Pei, C., Hou, B., "Experimental and theoretical investigation of the adsorption behaviour of new triazole derivatives as inhibitors for mild steel corrosion in acid media", Electrochim. Acta. 52, 2007, 6386-6394. DOI: $</$ b $>10.1016 /$ j.electacta.2007.04.077 


$$
\text { توليف جديد للمركب }
$$

3-[(4-BROMO-5-METHYLTHIOPHEN-2-YL)METHYLENEAMINO]-2-ISOPROPYLQUINAZOLIN-4(3H)-ONE وتثبيطه لتآكل الزنك في حمض الهيدروكلوريك

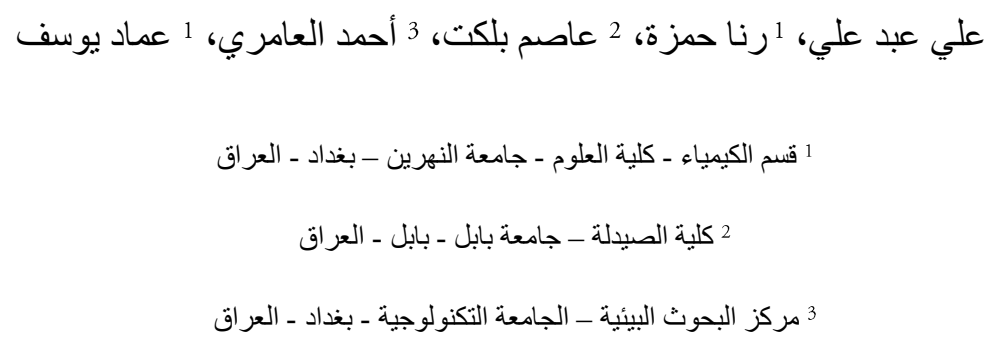

$$
\text { تم دراسة تأثنير المركب التالي: }
$$

3-[(4-bromo-5-methylthiophen-2-yl) methyleneamino]-2- isopropylquinazolin -4(3-H) one (3-4-5QZ)

كمثبط لتآكل الزنك في محلول حامض الهيدروكلوريك من خلال استخدام طريقة قياس نقصان الوزن. ووجد أن معدل التأكل قد نقص بزيادة نركيز المثبط. كما نم أيضاً در اسة ادمصاص الـ(5QZ-4-3) على سطح معدن الزنكل ووجد أنه يتبع نموذج فرويندلش. تم إستخدام طريقة الـPM3 و الحسابات الكمية الكيميائية لمعرفة الخو اص الإلكترونية لمركب الـ(5QZ-4-3) و النتائج تبين وجود نر ابط جيد بالمقارنة بالنتائج التجريبية المعملية. 